This article analyses the role of fetish-

unspoken attachments-within and against the 2020 proposal to restructure the College of Sciences at Massey University.l look at the roles played by three forms of fetish: the commodity fetish, the fetishisation of intellectual labour, and the fetish of knowledge-withoutconsequences. I analyse the restructuring and its opposition by mapping these fetishes and the deadlocks to which they lead. In addition to highlighting insights that the concept of fetish generates into the politics of the restructuring, I speculate on the role of fetish as a political factor in the contemporary moment. 


\section{Workplace Restructuring and its Discontents}

\section{WARWICK TIE}

Amid a series of issues that challenged my university's image as a bastion of free speech, I received an anonymous letter, seemingly from a colleague, calling me 'gutless' for my silence on these matters. The letter arrived at a time when management was busily pursuing plans to restructure the science faculty in ways that could impact significantly upon both staff and students. Much was at stake. My reason for not engaging was simple. The positions I heard from the university administration and from my colleagues reflected sets of unspoken attachments_-'fetishes'-from which politically conservative implications follow. The attachments included the ideas that university-based science pivots on evidence-based financial management and that 'scientific' (post-positivist) expertise is the primary source of evidence. In my mind nothing progressive, let alone transformative, could come from debates framed in these terms. At stake was not just the fetishistic form the ideas were taking, but also the way I might express my concerns. I could not suggest that these ideas had each become a 'fetish' without that criticism itself sounding 'fetishistic'. I was at risk of sounding fetishistic about fetish!

The impasse in my thought arose from the concept of 'fetish' feeling to me as if it was 'just so', (cor)responding in a 'natural' manner to how the ideas were circulating in the 
university. Associated with nature, even in this most indirect of ways, 'fetish' was at risk of becoming as blunt an instrument with which to understand the restructuring as a conclusive definition or a spanking paddle. That said, associations with 'nature' are difficult to sever. References to the naturalised features of concepts - of what Marx called the 'natural characteristic' of a concept, or its 'naturally determined factors'-enable the mind to connect ideas with reality. ${ }^{1}$ Perspectives on the naturalised features of concepts have ranged widely within Western thought, from those that associate these features with human sensual experience (as did Feuerbach) to those in which systems of logic predominate (as with Hegel). ${ }^{2}$ The naturalised features of 'fetish' can range from a natural human predisposition towards the erotic (fantasies of riding crops, laced leather, and the like) to a natural amenability to rational explanation (by which, for example, Freud interpreted fetish as a psychological mechanism through which the masculine subject moderates desire). ${ }^{3}$ Inescapable as the naturalised features of concepts appear to be, fields of social activity are at risk of being tied to the futures implied by their 'naturalised' forms — to futures associated with 'the erotic' ${ }^{\prime}$ or 'the logical' in the case of fetish. ${ }^{5}$ This trajectory needs to broaden if an analysis that draws upon fetish is to avoid accusations of being an exercise in self-satisfaction.

For the concept of fetish to create new and defensible insights into workplace restructuring, closer attention to methodology is required than is available from the concept's naturalised features. The brief sketches on methodology by Marx in his 1857 introduction to A Contribution to the Critique of Political Economy-reproduced as the opening chapter of the

1 Karl Marx, Grundrisse (London: Penguin Books, 1993), 110; A Contribution to the Critique of Political Economy (London: Lawrence \& Wishart, 1970).

2 Alberto Toscano, 'The Open Secret of Real Abstraction,' Rethinking Marxism 20, no. 2 (2008): 274.

3 Sigmund Freud, 'Fetishism,' in Standard Edition of the Complete Psychological Works of Sigmund Freud, vol. 21, ed. J. Strachey (London: Hogarth, 1961), 149-157.

4 Peter Fleming, 'Sexuality, Power and Resistance in the Workplace,' Organization Studies 28, no. 2 (2007): 239-256.

5 Linda Putnam et al., 'Discourse and Resistance: Targets, Practices, and Consequences,' Management Communication Quarterly 19, no. 1 (2005): 5-18. 
Grundrisse—suggests how this might happen. Marx's notes suggest that a key to the successful application of a concept like fetish lies with a change in the concept's composition. The composition of the concept needs to shift from its naturalised features to that of a 'concrete' expression of the concept. By way of illustration, Marx described how $17^{\text {th }}$-century political economists described areas of economic activity as if they were natural habitats of economic exchange: 'the living organism, the population, the nation'. They believed that knowledge of those habitats would create insight into 'the whole' to which economic exchange contributes. In contrast, in its 'concrete' form, the work performed by a concept never suggests 'a vague notion of a whole'. Instead, it points to 'a totality comprising many determinations and relations'. ${ }^{6}$ Rather than the 'whole' for which the minds of the classical political economists reached, there always already exists the singular reality within which thought itself functions-a totality whose contours defy full and final description.

The pathway from the naturalised features of a concept to its 'concrete' expression lies with the details of the specific situation to which the concept is being applied. As Marx observed: 'The most general abstractions [like that of fetish] arise on the whole only when concrete development is most profuse, so that a specific quality is seen to be common to many phenomena, or common to all. Then it is no longer perceived solely in a particular form'. ' Evidence that a concept has become concrete comes when the small range of 'naturalised' meaning that the concept once implied (of eros and logic in the case of fetish) has seeded further types of meaning without injury to the former. Through this process, a concept like fetish may thereby show itself at some point to have become 'concrete because it is the concentration of many determinations, hence unity of the diverse'. ${ }^{8}$

At first glance, Marx suggests, the state of knowledge produced from this 'unity of the diverse' might seem like a mere 'summing-up', a 'result'

6 Marx, A Contribution.

7 Marx, A Contribution.

8 Marx, Grundrisse, 101. 
of inquiry - but this is not so. ${ }^{9}$ Insights of more comprehensive kinds may continue to be produced as if 'in summation' of inquiry, but the object around which that understanding concentrates is the figure of 'totality'. Totality is 'the point of departure in reality [of physical existence] and hence also the point of departure for observation and conception [of human knowledge]'. ${ }^{10}$ For Marx, knowledge does not develop in a cumulatively linear way, starting from 'nothing' and then building towards a single state of universal understanding. Instead, as Marx suggests, knowledge is a movement of understanding. Knowledge in each period of history has a range of movement that is particular to the communities of that time. For example, the movements of knowledge within communities under feudalism differ to those of groups under capitalism, with those of an earlier industrial monopoly capitalism differing again from those of a now global financialised capitalism. These movements of understanding are themselves able to shift direction, as each is grounded not only in the current historical period but also by the totality in which human history exists in concert with the histories of others. The possibility of social explanation lies with the movement of understanding.

The analysis of workplace restructuring that follows draws on a capacity held by fetish that corresponds with the naturalised features of the concept - that the concept naturally supports logical explanation of the fields to which it is applied. Three kinds of fetish are involved. The first is 'the commodity fetish' that Marx had identified as being central to capitalist economy. ${ }^{11}$ Following this is a 'fetishisation of intellectual labour' ('expertise' we would now say) that Alfred Sohn-Rethel identified as being central to the culture of capitalist accumulation. ${ }^{12}$

Paying attention to each of these fetishes produces insights into the restructuring. For Marx, the commodity fetish is the social structure that

9 Marx, Grundrisse, 101.

10 Marx, Grundrisse, 101.

11 Karl Marx, Capital: A Critique of Political Economy, vol. I (London: Penguin Books, 1976), 163-177.

12 Alfred Sohn-Rethel, Intellectual and Manual Labour: A Critique of Epistemology (London and Basingstoke: Macmillan Press, 1978). 
masks the exploitative arrangements by which commodities are produced and by which the motion of value is sustained in its journey to realisation as capital. In the context of the restructuring, the commodity fetish appears as a reliance by the proposal's authors upon abstract measures of financial performance in relation to science research and teaching.

The fetishisation of intellectual labour is both related to and different from the commodity fetish. It describes the social status given within capitalism to work done with the mind over that done with the hands. The human mind works by creating abstractions of material reality and capitalist activity needs to corral this imaginative act on a routine basis so that raw materials can be turned into commodities. Rewards, including social status, help ensure the availability of intellectual labour for capital. This capacity for abstraction, and the social status associated with it, became central to the arguments made by university scientists against the proposal to restructure.

In addition to these two kinds of fetish is another that helps account for the letter criticising my lack of involvement in the debates. This is what the philosopher Alenka Zupančič calls the fetish of 'knowledge without consequences'. ${ }^{13}$ This fetish explains situations in which the possession of insights about a given issue comes to matter more than what those insights say about the issue. This fetish helps us understand in a non-moralising manner how people may behave in ways that are disconnected from what they claim to know.

Following Marx's insights into the possibility that a concept might shift from its naturalised features to a 'concrete' expression of itself, we can anticipate more from fetish than a set of insights into the dynamics of workplace restructuring. The development of a concrete expression of the concept lies with the possibility that its use in analysing situations might generate a new movement of understanding. To the extent that fetish gains this capacity, it will pass from being an 'analytical factor' in studies like this essay to a 'political factor' of the present period. But our starting point is

13 Alenka Zupančič, 'You'd Have to be Stupid Not to See That,' Parallax 22, no. 4 (2016): 413-425. 
to map a set of oscillations between the fetishes at play in the restructuring proposal and the political deadlocks to which these fetishes give rise.

\section{Between fetish and deadlock}

The proposal to restructure the science faculty at Massey University, released in February 2020, pointed to historical financial shortfalls in the operation of the College of Sciences as the reason for the restructuring-with an anticipated operating loss in 2020 of over $\$ 18$ million. ${ }^{14}$ A significant reform of the teaching curriculum is presented in the proposal as the way in which this shortfall can best be addressed. This suggestion would see a current duplication of courses across campuses eradicated, with each of the programmes in the college (biology, physics, maths, etc) located in a specific 'anchor' campus, ${ }^{15}$ with greater use of on-line learning for students than currently occurs, potentially affecting the employment status of one third of the university's scientists. ${ }^{16}$ Two kinds of empirical finding are presented in the proposal to justify the proposed changes: 'financial underperformance' of the college and 'low enrolments' relative to the size of the teaching curriculum. ${ }^{17}$ The conclusion reached in the document is that nothing short of a significant restructuring of the curriculum may resolve the matter of financial underperformance in the context of low enrolments relative to course offerings.

The proposal document reflects Aotearoa New Zealand's neoliberal reforms of the 1980s, in which market discipline was installed in the administrative systems of state agencies, including universities. In the university setting, this included a requirement that each institution

14 'Discussion Document: A Future Academic Plan for the College of Sciences,' Massey University, 2020.

15 The changes are significant for each of the campuses, with mathematics and computational sciences, for example, potentially no longer being taught on the Albany campus.

16 Jaime Morton, 'Massey shake-up: Over a third of academic science staff could go,' NZ Herald, 6 October 2020.

17 'Discussion Document,' 8-13, 15, 14-15. 
generate its own future additional funding (an 'operating surplus'), that greater attention be given to 'market demand' from students and employers, and that greater levels of flexibility be built into employment conditions such that universities could respond more promptly to changes in demand. This has given way to an increased reliance upon short-term contract employment as compared to permanent positions, ever-more differentiation of work tasks into financially calculable components, a greater use of quantitative audit processes to measure qualitative outputs, and stronger command ('line-management') structures. ${ }^{18}$ The restructuring proposal exemplifies the continuing influence of the idea of market discipline through its presentation of the college's situation as a set of econometric abstractions from which clear decisions are anticipated. These abstractions map patterns in profitability and cost onto the college's key tasks of teaching and research. ${ }^{19}$

\section{The commodity fetish}

In the terms offered by Marx, abstractions of the kind we see in the restructuring proposal reflect what happens as commodities circulate for sale. Marx called this process 'the commodity fetish'. For Marx, the production of commodities must always involve the exploitation by capital of people who have nothing to sell but their labour power. Thus, the generation of profit - surplus value-is predicated upon exploitative social relations. As commodities are presented for sale, those relations fall from view and, instead, the human relations that are involved take on the 'fantastic' form of relationships that the commodities have with one other. Relationships between commodities 'appear' in the place of the exploitative relations by which they were produced.

In the case of the restructuring proposal, the knowledge-producing practices that we call science take the form of representations of science-related activities (graphs of income and of expenditure, enrolment patterns relative

18 The most comprehensive outline of the logic can be found in the New Zealand Productivity Commission's 'New Models of Tertiary Education,' March 2017.

19 'Discussion Document,' 20-28. 
to offerings, and so on). The representations of performance appear in the place of science 'itself'. Only those representations enable science to appear as a calculable field, amenable to managerial administration. The excessive significance attributed in the restructuring proposal to these representations of science-related activity thereby reflects the operation of the commodity fetish.

The key word here is 'reflect', as there is no direct causal connection between how commodities circulate and how ideas operate. The way in which commodities circulate within capitalist markets does not cause science to be represented in the abstract terms of measurable performance indicators. The process of abstraction by which the restructuring proposal presents science does not thereby suggest what it is that makes the proposal 'capitalist'. At best, the restructuring proposal 'reflects' the processes of capitalist exchange. Indications of how the restructuring document came to participate in the commodity fetish lie elsewhere, in what the proposal cannot say.

What the restructuring proposal cannot discuss in any substantive way is, to use Marxian terms, the use value of science. By use value, we mean science as a set of secular practices of knowledge production that enhances human and other life. The president of the New Zealand Science Association, Troy Baisden, reaches towards this point in an observation he made about the organisational pathway along which the restructuring proposal travelled. The proposal bypassed the Academic Board, the group traditionally responsible in the university for the oversight of academic offerings. As Baisden writes: 'What is most concerning is that announcements appear to come ahead of internal consultation, including the traditional role of academic boards in allowing leaders in research and teaching to manage the impact of proposed changes'. ${ }^{20}$ Questions of science, Baisden's observation suggests, could thereby be put to one side. This side-lining of discussions about science per se carries on from the proposal document. References to science as a practice of knowing and of

20 Jaime Morton, “'Risky changes” - Massey shake-up alarms NZ scientists,' NZ Herald, 23 February 2020. 
its social value are of a cursory kind. ${ }^{21}$

In Sohn-Rethel's terms, the side-lining of discussion about science's use value in the restructuring process corresponds with a moment common to every commodity as it circulates in anticipation of its realisation as surplus value. This is the point at which the flow of time fragments: the 'use and exchange [value of commodities] are not only different ... but are mutually exclusive in time. They must take place separately at different times'. ${ }^{22}$ The use value of an object and its exchange value must occupy mutually exclusive time zones. The reason lies with the practicalities of economic exchange. Under capitalism, exchange requires the development of various abstractions of the object being bought/sold. The range of abstractions that are drawn upon pivot upon the sets of complexities associated with differences in place and time in the processes of production and exchange. Money becomes the most significant of those abstractions, as it operates as the 'universal equivalent' for all the other abstractions involved. Amid this array of abstractions, there is one object that cannot appear during the process of exchange: the object to be traded 'in itself' (the commodity). As Sohn-Rethel notes, consideration of the object 'is at a standstill, or assumed to be at a standstill, while the other practice, that of exchange, holds sway'. ${ }^{23}$ When I buy an apple from a greengrocer, for example, the apple needs to lie inertly on the counter while the transaction is completed. If I wish to check on the use value of the apple, to ensure that it is not rotting, for example, the process of exchange breaks and resumes only when I am satisfied that it remains an apple I want to eat.

The inability of 'science' to likewise appear in the restructuring proposal, to appear in its use value, has the effect of fetishising the econometric abstractions by which the restructuring document presents science as a field amenable to centralised administration. The abstractions take the place of science 'in itself' - with science per se unable to appear. Through those abstractions, the restructuring of science can take the form

\footnotetext{
21 'Discussion Document,' 3.

22 Sohn-Rethel, Intellectual Labour, 23-24.

23 Sohn-Rethel, Intellectual Labour, 27.
} 
of a simple calculation, as Baisden pejoratively puts it, of a 'blinkered' effort 'to improve on a single metric, such as cost per student'. ${ }^{24}$ This situation remains open to challenge, however, because the matter of science's use value could be introduced into discussion at any time. Indeed, opponents of the proposal do exactly this, but in a way that reinforces the proposal's abstraction of science in various indicators of performance. Following the lead of Sohn-Rethel, it cannot be otherwise under capitalist conditions.

\section{The fetishisation of intellectual labour}

The omission of science's use value from consideration 'in itself' occurs through the social status awarded by opponents of the restructuring to the same processes of abstraction by which the proposal turns science into a set of measurable indicators. In Sohn-Rethel's terms, the move turns upon a 'fetishisation of intellectual labour' (of scientific expertise), ${ }^{25}$ the possibility of scientific expertise comes from the social production of a type of mind that knows how to abstract. This mind has learned early on how to generalise from particularities. Moreover, it is a mind that knows itself to have been abstracted, that it has been set apart in the social order on account of its special abilities 'to know'. Indeed, the kind of idealised ego that emerges is able to say of itself that 'I am a scientist, a thinker, a philosopher, a writer', and so on, and is the outcome of an abstracting social system par excellence.

This kind of mind has very humble origins, developing amid the routine participation of people in the activities associated with capitalist economic exchange. Its normalisation is difficult to see from the inside of capitalist society. ${ }^{26}$ Connections between expertise and the capitalist economy develop in unconscious ways-'behind the backs of people', as Marx likes to say in Capital. The connections remain hidden because intellectual labour and capitalist economy intersect in what people do rather than what they think. 'The essence of commodity abstraction . . .

24 'NZ Association of Scientists reacts to concerns at Massey Albany,' Scoop, 24 February 2020.

25 Sohn-Rethel, Intellectual Labour, 13-17.

26 Sohn-Rethel, Intellectual Labour, 30. 
is that it is not thought-induced; it does not originate in men's minds but in their actions'. ${ }^{27}$ This mechanism by which capitalism is installed within subjectivity is the 'open secret' of capitalism: we all know that we routinely participate in the practices of capital yet may believe ourselves to be immune to their stratifying effects. ${ }^{28}$ For Sohn-Rethel, the relation between the fetishisation of intellectual labour and the operation of capitalist economy does not occur in an indirect manner, connected 'only [by] analogy', as we have with the relation between the restructuring document and the commodity fetish. The relation is instead of a direct kind, being one of 'true identity'. ${ }^{29}$ The direct nature of the process influenced how opposition developed toward the restructuring proposal.

The fetishisation of intellectual labour shaped how arguments against the restructuring formed. The expertise held by scientists, for example, is presented by opponents as a scarce resource which Massey University is at risk of losing to other institutions. 'Bright flight' will occur, with those left being 'far less successful in delivering research excellence and shepherding students toward successful careers'. ${ }^{30}$ In this vein, Professor Peter Schwerdtfeger, speaking of the specific losses that science at Massey Albany faces, observes: 'We have people here who were head-hunted by Oxford University, we have three Rutherford Fellowships going up here in Albany, we have a Rutherford medallist in Albany, we have highlyacclaimed international researchers and now they want to shut it down? It's unbelievable'. ${ }^{31}$

The notion of scientific expertise also shapes how one argument is made that science has a social use value. In a public address on the restructuring proposal, Professor James Dale grounded his opposition in the idea that science has a use value that cannot be captured by administrative calculation:

27 Sohn-Rethel, Intellectual Labour, 20.

28 Toscano, 'The Open Secret of Real Abstraction.'

29 Sohn-Rethel, Intellectual Labour, 7.

30 Morton, 'Risky changes'; 'NZ Association of Scientists reacts.'

31 'Science is Thrown into a Restructuring Crucible at Massey University and in NCEA Courses,' The New Zealand Institute of Agricultural \& Horticultural Science Inc. 
the impact we ... have goes far and wide. We do fundamental discovery here: yeah that's our business but this is the kinds of discoveries that can inspire the community and get lots of media releases like the discovery of new planets. We do basic research that's fundamental for health concerns like using mathematical modelling to uncover potential new ways to treat heart disease or predicting the spread of diseases using math which is as we know an incredibly important field right at this moment. ${ }^{32}$

On the face of it, such a statement appears to do what Sohn-Rethel says cannot be done: the use value of science can be introduced into transactional-type discussions. Science 'impacts' upon society. It thereafter appears possible to suggest that science has an inherent social value that cannot be reduced to financial calculation. Things are not so simple, though. The issue of science's use value is articulated here through the very same fetishised intellectual labour by which the restructuring document abstracts science into an array of performance indicators. The use value of science to society cannot appear 'as such', for two reasons. First, science is presented here as a form of academic expertise that acts upon the publicthe impact of science is 'our impact on the community'. ${ }^{33}$ Here, scientific knowledge primarily moves in one direction, from scientists to the public, and subsequent mentions of 'partnerships' and of 'outreach' are coloured by this assumption. Second, talk of what science 'is' sees science become a set of (expert) actions upon a world external to science, upon a world that is assumed ready and waiting for scientific measurement. In conjunction with this assumption, scientific practice pivots upon-it 'is'-a technical process. It tests hypotheses that have been abstracted from general theories, for which the measure of success is the prediction of future states. It is thereby asserted that the loss of Massey's contribution to the global networks of predictive activity will make the world a risker place to be. ${ }^{34}$ Framed in these ways, science becomes a set of actions done to the world rather than

32 'Prof James Dale argues to keep Sciences at Massey University's Albany Campus at 26/2/20 PVC Forum,' YouTube, 27 February 2020.

33 'Prof James Dale,' emphasis added.

34 'Prof James Dale.' 
being a part of the world: scientists become 'the exception' to that world. The use value of science cannot be contemplated outside the operation of scientific expertise, outside the fetishisation of intellectual labour.

Our interest in this framing of opposition to the restructuring lies with a deadlock in which the opponents unexpectedly find their position mired. The deadlock turns upon a fundamental point of agreement that emerges between arguments both for and against the restructuring. The opponents' dependence upon arguments that fetishise intellectual labour annuls antagonism in the debate. It replaces antagonism over 'questions of science' with disagreement over points of difference on the administration of science. Such 'points of difference' raised by scientists in the debate include the matter of 'academic representation' within senior management, ${ }^{35}$ the 'rates of financial contribution' made by science to the centralised administration, ${ }^{36}$ how a new science building at Albany is being funded, ${ }^{37}$ and the 'timeline' for resolving financial underperformance. ${ }^{38}$ In one register, this participation in questions about the administration of science looks like an unintended consequence of the opposition. The scientists who speak up do not, of course, intend their opposition to support the underlying tenet of the restructuring document- that the matter can be primarily resolved through a transactional analysis of administrative processes.

Viewed from Sohn-Rethel's perspective, however, that effect is not unexpected. Questions of use value have been separated off from the processes of abstraction by which the proposal makes its argument. This is not to say that the use value of science can ever become clear under capitalist conditions — scientific practice cannot presently stand outside the fetishisation of intellectual labour upon which production under capitalism depends. At best, the idea that science has use value can be gestured towards,

\footnotetext{
35 Morton, 'Risky Changes.'

36 New Zealand Herald, 'Angry Massey Scientist.'

37 'Prof James Dale.'

38 'Anger Over Massey's Plan to Switch Teaching Locations,' Times Higher Education, 6 March 2020.
} 
and this is what the opposition does. To the extent to which opposition to the restructuring succeeds in pointing to that use value, however, it does not introduce antagonism to the debate. Instead, it introduces 'difference' into how opposition toward the proposal will proceed. What follows within the debate is not a challenging of the equation by which the proposal to restructure computes science, but something more akin to discussion over which elements ought to be included in that equation.

\section{The fetish of knowledge without consequences}

In early December 2020, a brief message from the senior leadership team indicated that the restructuring would go ahead, beginning 2021. It is in this context that the letter arrived criticising me for not contributing to the debate. On the face of it, the letter could be interpreted in the simple psychological terms of one individual's anger toward me. Alternatively, in sociological terms, the letter signalled an apparently intentional erasure of myself and unintentional erasure of the writer. The erasure of myself follows the pattern of Stalin's show trials, as described by Slavoj Žižek. ${ }^{39}$ I am accused of something that, at the level of appearances, I am guilty: I did not speak up in the debate. Further non-participation demonstrates my obvious guilt. The letter now provides me with the opportunity to admit to my guilt and thereby achieve redemption. But the appearance of that possibility is a ruse. Redemption can never be attained because any admission of guilt on my part-I did not speak-will indicate the truth of the deeper accusation being made-that I am intrinsically 'gutless'. Whichever way I turn, I'm toast.

The letter also signals the erasure of the author. The author participates in the two fetishes at work in and around the restructuring-of the commodity fetish and the fetishisation of intellectual labour. They do so by telling me that they believe in 'freedom of speech', the academic as 'critic and conscience of society', and 'democracy'. Moreover, they tell me they possess special knowledge: they know that the prospects for democratic life

39 Slavoj Žižek, 'The Fetish of the Party,' in Lacan, Politics, Aesthetics, eds. Willy Apollon and Richard Feldstein (Albany: State University of New York Press, 1996): 3-30. 
turn upon the defence of rights to speak out, along with the role of critic and conscience. Of what kind of knowledge is this, however, given that its primary effect is erasure?

It is a kind of knowledge, Zupančič suggests, in which the act of possessing an insight into a given situation matters more than what the insight says about the situation. Zupančič goes further: what the insight says, its content, falls from the personal awareness of the one who speaks. In psychoanalytic language, the individual disavows understanding of the knowledge they hold. From that point on, actions are decoupled from that knowledge. For Zupančič, knowledge takes on this kind of structure when meaningful responses to an antagonism are placed out of reach to those impacted by that antagonism-where the discursive framing of a situation restricts agency while appearing to do the opposite. This framing occurs through the operation in the restructuring of the commodity fetish and the fetishisation of intellectual labour. Energies are thereby diverted away from 'knowledge held' and towards actions that operate without reference to that knowledge. A kind of action that is 'without consequences' can thereafter happen that may mistakenly pass for political agency.

It should be noted that the sense of a sequence that runs through my account of fetish in the restructuring process-from 'commodity fetish' to 'the fetishisation of intellectual labour' to the fetish of 'knowledge without consequences'-reflects the need to tell a story. There is no necessary succession in the fetishes and the various appearances that fetish takes are distributed in a way that is more spatial than temporal, strewn across different sites and subject positions. No single type of fetish, nor their deadlocks, necessarily belongs to one place or one position. Rather, it is through oscillations between them that positions form. It is from this spatial distribution of fetish that a transition might occur from the 'naturalised features' of fetish to a concrete expression of the concept and of a transition of fetish from an analytical factor in sociological inquiry to a political factor in social struggle. 


\section{Towards fetish as a political factor}

My attempt to avoid a 'fetishisation of fetish' in this account of workplace restructuring turns upon a transition of 'fetish' as a field of naturalised features to what Marx called a 'concrete' expression of the concept. My analysis of the proposal to restructure science at Massey draws extensively on the 'natural' capacities of the concept to generate explanations for what has occurred. Attention to this feature of fetish has seen me talk about the roles played in that restructuring by the commodity fetish, the fetishisation of intellectual labour, and the fetish of a knowledge that is without consequences. A diversity of insights come from the use of fetish in this way. It is through the 'unity' of those insights that a pathway lies toward the 'concrete', and towards fetish becoming a political factor in the current period. This pathway runs askew to, without disregarding, the concerns animating both the proposal to restructure the College of Sciences and its opposition.

Each of the positions taken within the university speak as if the object of their concern is 'science'; however, in each instance, the object becomes something else: a set of representations of science-related activity. For the authors of the restructuring proposal, for example, those representations are of financial performance indicators around research and teaching. For the scientists who oppose the proposal, the representations are of the intellectual labour ('scientific expertise') at risk of being lost in the restructuring. The key point is not that the referent, 'science', will fail to materialise despite progress that might be made in the debate. Following Marx's notes on methodology, the hope that this could happen reflects a mistaken belief that well-intentioned thought and action will bring 'wholeness' to science. The key point is that a collective state of disavowal operates throughout the debate. It is collectively understood, without being acknowledged, that the object of discussion—science as such—cannot appear. In conjunction with this, debate finds itself corralled into questions on 'the correct' representation of science.

This state of shared disavowal accords with a range of contemporary 
observations about the structure of social explanation under late capitalism. ${ }^{40}$ These observations point to a new state into which knowledge has entered. Work undertaken with ideas mimics a capitalism that increasingly depends upon its coding of life in ways which support financial speculation. This increasing abstraction of life into financial fictions affects in very mundane ways the explanatory work performed by knowledge workersfor example, a shift in the philosophical structure of explanation that sees 'why' questions replaced by those that ask 'how and where'. ${ }^{41}$ Questions that ask why events occur are notoriously difficult to answer because of the array of determinates that are inevitably at play. Complexities associated with times and locations come into play along with differences in the effects experienced by diverse groups. Moreover, the greater the speculative elements of such inquiry, the more that questions and their answers need the guidance of metatheories in which only the true believers have real faith. Despite these problems, for David Harvey, strong social explanations turn upon publicly defensible answers to the question of 'why?' ${ }^{2}$ Following Marx's notes on methodology, the answers that come from asking 'why' will necessarily reflect the diversity of socio-cultural situations drawn into that question. Answers will be complicated.

In contrast to 'why' questions, the questions that ask 'how' are much easier to grasp. They are easier because the answers given to 'how' questions tend to draw their content from already-existing and locally occurring social processes and mechanisms. The directions that answers will take are, in contrast to those associated with 'why?', easy to see. Debate on the restructuring is of this kind: how might better management of science occur? How might scientific expertise be recognised amid financial cutbacks?

40 Guy Debord, The Society of the Spectacle (New York: Zone Books, 1994); Fredric Jameson, Postmodernism, or, the Cultural Logic of Late Capitalism (London: Verso, 1991); Jean-François Lyotard, The Postmodern Condition (Manchester: Manchester University Press, 1984); Alenka Zupančič, What is Sex? (Cambridge, MA: The MIT Press, 2017); Slavoj Žižek, The Ticklish Subject: The Absent Centre of Political Ontology (New York: Verso, 1999).

41 David Harvey, 'Realization Crisis and the Transformation of Daily Life,' Space and Culture 22, no. 2 (2019): 126-141.

42 Harvey, 'Realization Crisis,' 126-127. 
Herein lies a paradox. Insofar as some of the issues being faced by science originate in places beyond the university and before the current period, the situation calls for the asking of 'why' questions. As Harvey suggests, we should 'step back and ask the question. ... Why does it seem so inevitable? Why is it that it seems so impossible to say, "no, no, we do not want that"? Why can we not make something different? If capital is about freedom of choice why is it that this future is foretold?' ${ }^{43}$ Accounts of this kind remain academically difficult to achieve, though. Marx's notes on methodology harbour another possibility.

The state of unification for which Marx reaches is between the movements of explanation found within the diversity of detail which any scientific inquiry produces, and the socio-historical context in which that inquiry is conducted. The lodestone of that unification is not an imagined point of wholeness to which the diversity of findings will lead, but the alwaysalready-existing totality to which both the movement of explanation and socio-historical context belong. 'Totality' enables the domains of both social explanation and socio-historical context to move in relation to one another, with this potential for simultaneous movement mediated by concepts able to develop into a 'concrete' expression of themselves. The extent to which a concept like fetish succeeds in moving from an analytic factor that generates new insight (into a situation like workplace restructuring) to one that eases the movement of explanation amid a devaluation of strong explanation, is the extent to which that factor becomes 'political'. No recipe exists in Marx's work, however, to indicate how this might happen.

As to whether fetish might pass from being an analytic to a political factor lies beyond the present piece. There are, nevertheless, reasons for thinking that it may have this potential. First, the concept of fetish brings attention to how ideas might 'grip' the minds of people to such an extent that they act like a 'material force' upon them, as Stuart Hall put it. ${ }^{44}$ And second, fetish successfully links the movement of ideas with capitalist logics

43 Harvey, 'Realization Crisis,' 135.

44 Stuart Hall, 'The Problem of Ideology: Marxism Without Guarantees,' in Marx: 100 Years On, ed. B. Matthew (London: Lawrence \& Wishart, 1983), 59. 
in ways that can distinguish between those links that are direct and those that are not.

It is not clear whether such reasons are strong enough for us to remain hopeful about the concept. That matter is, however, beside the point. A greater reason for hope lies with a shift that happens to the temporality of the concept as it passes from the status of 'analytic' to 'political'. A transition in the concept of fetish from an analytic expression of its naturalised features to a concrete political factor cannot be witnessed as it occurs. In the present moment, the role that fetish plays in specific areas of social life (such as workplace restructuring) become evident through the diversity of the explanations to which the concept's naturalised features give rise. Whether or not the diversity is sufficient to change how social explanation works in such studies, and to what extent any such changes might contribute to an exit from the representationalist deadlock(s) of the current period, will only become visible in reflections made later on about this period. To the extent to which an observer in the future sees that fetish has indeed contributed to such a movement, the concept may take on the form of a 'vanishing mediator', ${ }^{45}$ a concept that has helped to 'make things happen at a particular time, after which their time [was] up'. ${ }^{46}$ Only in retrospect, then, might 'fetish' take on the appearance of a political factor for this period. For those of us living through the current moment, only the naturalised features of the concept are at hand to help us analyse situations: the impress of riding whips and/or of reasoned accounts. Fetish will be available as a political factor only to those who might later enjoy the social effects of the concept having become concrete.

45 Fredric Jameson, 'The Vanishing Mediator: Narrative Structure in Max Weber,' New German Critique 1 (1973): 52-89.

46 Gregor McLennan, 'Travelling with Vehicular Ideas: The Case of The Third Way,' Economy and Society 33, no. 4 (2004): 485. 